\title{
Realization of Didactic Potential of National Pedagogic in Pedagogical Process of School: Essence and Principles
}

\author{
Negmatzhan Almetov \\ Pedagogical sciences doctor, M. Auezov South Kazakhstan State University \\ Email:n_almetov@mail.ru \\ Kulimkhan Arymbayeva \\ Pedagogical sciences doctor, M. Auezov South Kazakhstan State University \\ Email:medeu07@mail.ru \\ Lazzat Buletova \\ Pedagogical sciences doctor, M. Auezov South Kazakhstan State University \\ Email: buletova05@mail.ru

\section{Tursunkan Kashaganova}

Pedagogical sciences candidate, M. Auezov South Kazakhstan State University

Email: kashaganova67@mail.ru

\section{Gulnur Narymbet}

Master of history, M. Auezov South Kazakhstan State University Email:n.gulnur_85@mail.ru

Doi:10.5901/mjss.2016.v7n1p419

\begin{abstract}
Pedagogical process at comprehensive schools with national training language can be an effective factor of pupils' ethno cultural education under a condition when the didactic potential of national pedagogic ideas and experience is purposefully and systemically realized. Authors mean national training ideas and didactic experience which is empirically saved up by people at large reflected in national pedagogy sources, in folklore works, in folk customs and traditions, national thinkers' views economic and cultural traditions, folk art and traditional religion by the didactic potential of national pedagogic. Realization of national pedagogic didactic potential promotes four main functions - broadcasting, developing, differentiating, integrating, in modern school practice proceeds in unity of educational and extracurricular activities. The essence of this realization consists in use of national pedagogic ideas and experience through the ethno cultural focused content of education, in formation of pupils' traditional national knowledge and action ways, world outlook, moral and esthetic ideas.
\end{abstract}

Keywords: national pedagogic, didactic ideas, national didactic experience, didactic potential of national pedagogic, ethno cultural education, comprehensive school, realization, essence, principles.

\section{Introduction}

The problem of use of elements of national pedagogic in teaching and educational process of modern school is connected with revival of national school, with acceptance across the nation of idea of ethno cultural education which means "creation of the national system of training and education which is based on the idea of cultural and linguistic pluralism combining world level of technical and information equipment with traditional cultural values" (The concept of ethno cultural education, 1996).

Reorganization of educational and educational process of national schools on the basis of revival of national values in combination with the advanced universal culture, regionalization of education and development of conceptual bases of national education considerably stabilized process of realization of educational and didactic potential of national 
pedagogic in school practice. Problems of statement of national education most of all affect experts teachers, parents, executives of an education system, scientists, cultural figures and arts as preservation of interethnic stability, the statement of patriotism, ethnic revival of the people occupying the multinational sovereign state are a necessary condition of ensuring national equality without which it is impossible to form democratic society. On the other hand, as it was already noted, there is a pressing need of satisfaction of ethno cultural requirements of the nations of the country. Not for nothing in recent years in the CIS countries tens scientific conferences, seminars, meetings on questions of formation of national education and education in which scientists made valuable suggestions on improvement of national system of training and education were carried out the Scientific-theoretical analysis of literature on problems of national education and education allows us to mark out the following its features:

- the purpose of national education and education - development and formation of the personality on the basis of national values, centuries-old national social historical experience in combination with universal culture, education versatile perfect, highly moral and spiritually rich person.

- on the basis of national education and education preservation and reproduction of national shape of the personality is provided.

- the national culture of the personality is formed and develops, the national consciousness is formed.

- revival of historical memory of the people and assignment of the personality by it is provided.

- $\quad$ purposes of school programs whenever possible as much as possible come nearer to national understanding of the purposes of training and education.

- the maintenance of school education, out-of-class and out-of-school educational work are enriched with the traditional forms borrowed from national experience, methods and tutorials and education.

- $\quad$ the new subject matters providing studying of national culture, art, labor and moral experience, religious views are entered into the content of education.

- educational and educational process is based by the principle of an optimum combination modern with traditional, i.e. achievements of pedagogical science and the advanced school practice with progressive ideas and experience of national pedagogic.

- interest of pupils in religious knowledge goes for mastering of moral cultural wealth them.

Development of vitally resistant concept of national school can't be carried out today until modern teachers don't manage to return, master and realize the richest arsenal of pedagogical wisdom of the people in practice. We have to listen to what learns the people having centuries-old experience of training and education of younger generation (Orlova, 1991).

Due to the updating and change of the purposes and tasks of national school the tendency to formation of national education and education by realization of educational and didactic potential of national pedagogic is accurately traced. As it was already noted, within teaching some subjects of a natural-science and humanitarian cycle and especially labor preparation, in a solution of the problem of realization of elements of national pedagogic certain steps are taken. For example, programs for labor training, music, the fine arts and physical culture of national schools of the Republic of Kazakhstan were filled with ethno cultural material.

Testifies also that fact to importance and timeliness of statement of a question of realization of didactic opportunities of national pedagogic for school subjects of all cycles that in new standard programs need of widespread introduction of experience of national pedagogic in teaching and educational process is specially emphasized. So, in an explanatory note of new standard programs for initial classes of schools with the Uzbek language of training of the Republic of Kazakhstan it is noted that this subject "focuses teachers to solve the problems following from requirements of modern times-to adapt each branch to conditions of our region, whenever possible to nationalize them" (Standard programs, 2012, 4). However in reality insufficient awareness of teachers didactic opportunities of national pedagogic, lack of an evidence-based technique of realization of ideas and experience of training of the people interfere with achievement of the program purposes of training in school subjects. In general the pedagogical science is faced by an actual problem of permission of the existing contradiction between an objective tendency of updating of the contents and process of national education and education through realization of didactic potential of national pedagogic and insufficient study of this question in the theoretical plan.

\section{The Methods of Research}

When studying a problem we used methods of the theoretical analysis of references, studying of directive documents concerning a development of education historical and genetic and retrospective analysis of ideas and experience of national pedagogic, studying and synthesis of the best and innovative pedagogical practices. 


\section{Analysis of the Objective}

The historical and genetic analysis of a problem of didactic opportunities of national pedagogic is possible only on the basis of its direct connection with studying of history of development of pedagogical thought, in particular didactic views and theories in a retrospective. From this point of view works of classics of pedagogic Ya. A. Komensky, I. G. Pestalozzi, K.D.Ushinskiy, P.P. Blonsky are analyzed and once again the opinion that "the ethnic pedagogic takes theoretical sources in classical pedagogic" (Volkov, 2003) is confirmed. Is shown that studying of didactic potential of national pedagogic is connected with development the didactic of ideas, registration of didactics as sciences, with its further development in works of scientists-teachers.

In the context of studying of genesis of the problem investigated by us M.V. Boguslavsky's work in which it is convincingly proved is interesting that the advanced teachers and figures of Russian education of the beginning of the XX century stated valuable ideas concerning statement of national education, the maintenance of forms and methods of studying of traditional experience of education and training at comprehensive school (Boguslavsky, 1998).

Meanwhile, In the 20th - the 30th years of the XX century at domestic schools a certain positive experience of use of elements of national pedagogic in teaching and educational process is saved up. At school the using of national pedagogic in education of younger generation to what documents and publications of those times testify was provided. Purposes of school programs came nearer to national a understanding of education and training, and the new school began to be guided by local economic inquiries. Programs of all subject matters of complex knowledge of life, customs, cultures of the people. There were new forms of a teaching and educational which purposefully made use of experience of national pedagogic. Ideas of national pedagogic were successfully used in a teaching and educational and yielded fruitful results (Orlova, 1991). Shows researches of scientists-teachers that outstanding teachers of that time - A. S. Makarenko, P.P. Blonsky, S. T. Shatsky, etc. (Kozhakhmetova, 1998, 10-11] were supporters of effective application of experience of national pedagogics. In heritage of outstanding Kazakh educators of that period Zh. Aymautov, A. Baytursynov, M. Dulatov, H.Dosmukhamedov, etc. ideas of the organization of training and education at the Kazakh school on the basis of centuries-old national traditions of training and education are accurately traced (Kaliyev et al, 2009).

Historical and pedagogical works show that if in the first Soviet school documents democratic ideas, conformable to the best ideals of Russian pedagogic that, since 1930th years and in the subsequent, is observed alienation of centuries-old national pedagogical traditions from school. The school gradually came off national roots. The national school came to a crisis state.

Obvious revival of researches in the field of ethno pedagogic in the former Soviet Union is observed after 1991 when the former Soviet republics found the state independence. Adoption of national legislations on education, development and deployment of conceptual provisions of education and education of the studying youth, attempt of creation own the national of models of education - all this served of ethno pedagogical researches, expansion of their subject.

In recent years there was a row the pedagogic of the works concerning problems of ethno didactic approach to the maintenance of national education F.G.Yalalov's Monograph "Ehtno didactic" it is possible to estimate as a big contribution to research of didactic opportunities of national pedagogic (Yalalov, 2004). R.K. Dyusembinov are developed theoretic-methodological aspects and conceptual bases of introduction of the Kazakh ethno pedagogic in teaching and educational process of school (Atamuratov, 1991).

As a result of the analysis of literature it became clear that now such aspects of the problem investigated by us found reflection in literature: didactic ideas in oral creativity; didactic views of thinkers of the past; the national ideas and experience of training considered in the context of traditions of intellectual, physical, labor and esthetic training; the didactic potentiate families and its use in school practice; private and methodical questions of use of elements of national pedagogic when training in school subjects and in out-of-class work. In general it is possible to note that out of sight of authors there is a theoretic-methodological judgment of essence and features of national didactic ideas and experience of Central Asia and Kazakhstan, pedagogical bases of their realization. Description of the research.

Process of realization of didactic potential of national pedagogic, first of all, promotes implementation of four main functions of ethno cultural education, is guided by the solution of these main objectives:

a) broadcasting (ensuring integrity and reproducibility of ethno national communities);

b) developing (formation and development of national consciousness);

c) differentiating (identification of national and cultural needs of the person, ethnic groups);

d) integrating (ensuring interaction, interpenetration and mutual enrichment of cultures, integration of the personality into systems of world and national culture) (The concept of ethno cultural education, 1996). 
In modern school practice process of realization of didactic potential of national pedagogic proceeds in unity of educational and extracurricular activities. The essence of this process consists in optimum use of experience of national pedagogic in the substantial and procedural party of didactic work at school and by means of it is in formation at pupils of traditional national knowledge and ways of action, world outlook and moral and esthetic ideas, and by that in contribution of realization (performance) of the main functions of ethno cultural education.

School students acquire bases of the traditional national knowledge, ways of action, world outlook and moral and esthetic ideas from national experience generalized and systematized in the content of education at a lesson. In extracurricular activities the mastered national knowledge goes deep, extend and develop, and also traditional forms of occupations are taken.

\section{The Realization Principles}

We refer to the principles of realization of didactic potential of national pedagogic:

- the accounting of regional specifics of life of the people (ethnos) in the content of education;

- an optimum combination traditional and modern in educational and educational process;

- realization of experience of national pedagogic through all forms of activity of pupils;

- accounting of fundamental rules (principles) of national pedagogic;

- communication with programs of national development at the present stage;

- individualization of educational activity;

- moral and esthetic principles.

At once we will note that the allocated principles of realization of didactic potential of national pedagogic, on the one hand, are based on quite certain regularities (social and philosophical and pedagogical), first of all, substantially they are interconnected with regularities and the principles of training. On the other hand, the general principles of realization of didactic potential of national pedagogic, in turn, are transformed to more private rules corresponding to them. In brief we will characterize these principles.

\subsection{Principle of people life regional specifics}

The principle of accounting of regional specifics of life of the people reflects need of the account for formation of the maintenance of national education and education of features of economic, socio-historical and cultural and community life of this ethnos in the content of education. Realization of this principle is urged to eliminate the existing "gap" consisting available unequal "starting" conditions of development of the nations in general, and ensuring ethno cultural requirements and in the field of education, in particular. The success and quality of training of children of different nationalities and ethnic groups, its return are in many respects caused by acceptance in attention of features of the developed national tenor of life. Regional specifics of life of the people of Central Asia and Kazakhstan from the very beginning were defined by the following conditions:

1) mainly "agrarian orientation of economy, and therefore, customs, traditions, life, psychology of the people, its social composition; 2) existence of the big, including not one generation large family acting both in the city (craft) and in the village a direct work collective; 3 ) a combination of traditional forms of the agriculture based on systems of an irrigation in valleys of the rivers with so traditional forms of cattle breeding economy on the most part of the territory of the region, and, therefore, prime responsibility of the government for preservation and development of irrigational systems and the general conditions of ecological equilibrium in the region; 4) the power of patrimonial customs and the relations, including also the forms of mutual aid inherited from medieval craft (shop) production and a way of life; 5) Islamic orientation of all inherited culture (Kharlamov, 1997, 22). These and other main lines of life of the people of Central Asia, it is necessary to consider in development of the content of formation of national school that is one of the main ways of realization of the called principle. Didactic ideas and experience of national pedagogic find introduction in school practice through implementation of the principle of the accounting of regional specifics of life of ethnos.

\subsection{Principle of optimum traditional and modern combination}

The principle of optimum traditional and modern combination in educational and educational process demands that in educational and educational process the didactic potential of national pedagogic on the basis of its reasonable combination to achievements of modern pedagogical science and school practice was creatively used. Didactic ideas and experience of the people are selected from sources of national pedagogic through a prism of their accord to the purposes 
and problems of education and training at the present stage of social development. Not any elements of didactic experience of the people, i.e. not all ideas and the approaches to training of the child which developed in the people are progressive, expedient for application. Therefore, only proceeding from requirements to formation of the personality, purposes of national school, pedagogical value of traditional national experience of training, it is necessary to select its elements for inclusion, both in the contents, and in process of didactic work. The given principle demands existence of evidence-based selection of didactic ideas and experience of the people, allocation of the certain criteria revealing and measuring their expediency, an optimality for realization in the substantial and procedural moments of training at modern school. Later we will consider pedagogical requirements to selection and realization of material from experience of national pedagogic.

The specified principle also demands not to "abuse" elements of national pedagogic in design, the organization and carrying out lessons and other forms of occupations that is often allowed in practice of national schools. As real practice of introduction of ideas and experience of national pedagogic in teaching and educational process of school shows, for mass pedagogical experience of teachers artificiality in use of elements of national didactic experience is characteristic. The last are applied "not on the place", integrally don't enter the contents and process of training at a lesson, and sometimes turn this work as if into end in itself.

\subsection{Principle of national pedagogic experience realization}

The principle of realization of experience of national pedagogic through all forms of activity of pupils contains the personal and active concept of education in the basis. According to it, that "personal development of the person happens only thanks to "assignment" by it of public experience in its most various manifestations" is natural (Konstantinov, 1982, 83). This principle of realization of didactic potential of national pedagogic following from this regularity supports inclusion of pupils of national schools in different types of activity in which contents national experience is reflected. Practically all possible forms of activity of school students (the doctrine, socially useful work, game, public work, sports and improving and art and esthetic activity) have favorable conditions for filling of their contents progressive experience of national pedagogic. Same development of various parties of the formed personality on the basis of national values, centuries-old national experience is provided.

Bright example of realization of the principle formulated by us is the technologies of training in school subjects developed and applied by the advanced subject teachers in which attempts to include experience of national pedagogic it in the maintenance of these or those forms of activity of pupils at a lesson and in nonearning work are made. For example, labor traditions of the Kazakh people join in the contents and process of labor training of school students, or local history material and national and art traditions are used in the course of art education of pupils. At lessons of physical culture national games are widely applied, and as means of increase of interest of the doctrine of school students data from national physics serve in a school course of physics. Meanwhile, in educational process elements of national mathematics facilitate digestion of program material by pupils, form mathematical knowledge and abilities of school students, etc. When planning a lesson the teacher is called, whenever possible to provide inclusion of elements of national pedagogic in them, to achieve that national experience was reflected in all set of kinds of activity of school students conformable to the purposes and problems of didactic process, and the pupil took part in all from them. Development of pupils in all directions is provided only when all called activity forms in which are optimum combined traditional national experience with modern achievements of pedagogic and school practice in a complex are organized.

\subsection{Principle accounting national pedagogic fundamental rules.}

According to this principle, at realization of didactic potential of national pedagogic it is necessary to consider such major principles of national pedagogic as a nationality, a culture and nature conformity of education, education by work, communication of education with life. Didactic ideas and experience of the people proceed from the principles of national pedagogic, are under construction on their basis. The same principles played a part in development of didactic systems in the history of pedagogic. At realization of didactic potential of national pedagogic we face a question of inclusion of traditional national knowledge in the kept woman of school education, use of didactic views and experience of the people in the course of training. Means, need of the accounting of requirements to "assignment" by the identity of traditional national knowledge and experience which exist in the most national pedagogic is created. We will explain it on the example of the principle of level of culture of education according to which "at education it is necessary to take conditions of a place and time in whom the person was born into account and he should live, in a word, all modern culture in broad and comprehensive sense of the word" [Dyachenko, 1989, 87]. In teaching and educational process of school realization 
of this principle assumes special selection of national knowledge and labor experience taking into account local customs and traditions, economic living conditions of this region, a material state and level of culture of aboriginals.

\subsection{Principle of communication}

Principle of communication with programs of national development. Studying of all complex of national values in the conditions of school education can't be presented without their communication with the most important directions of national revival, economic and socio-cultural development of the sovereign national state. Ethno cultural education is caused, first of all, by public requirements, is inseparably linked with spiritual bases of tactics and strategy of development and strengthening of national statehood. Therefore, planning and the organization of process of realization of ideas and experience of national pedagogic in teaching and educational process of school contacts problems of development of the Kazakhstan society on the near-term and far outlook, reflected in directive documents, and also in annual Messages of the Head of state to the country people. Realization of didactic potential of national pedagogic in practice of teaching and educational process of school is connected with problems of spiritual revival of our society, transfer to younger generation of centuries-old progressive social experience of the Kazakh people and other people of the republic, improvement of quality of training and education of school students by the maximum adaptation of the contents and process of education to ethno psychological features and mentality of the Kazakhstan people, and not less important education of the Kazakhstan patriotism and culture of interethnic communication at younger generation.

Analyzing the given principle, it is possible to allocate from it such rules which are recommended to be considered in activity of teachers on realization of ideas and experience of national pedagogic:

1. Specially to pick up and include the convincing examples illustrating a role of national traditions, national art, language, religion and other values in the course of national revival, strengthening of the national sovereignty and statehood in the content of training.

2. To study the inherited cultural values, to solve educational contradictions and problems in connection with the leading program installations of national development, economic and socio-political problems of the young sovereign state in the conditions of a transition period.

3. To use opportunities of a training material from experience of national pedagogic in awakenings at pupils of national feelings, restoration of historical memory, awareness of need of national unity for creation of necessary conditions for full development of each nation and a nationality in the conditions of democratization of society.

\subsection{Principle of educational activity individualization.}

It is known that quality of the knowledge and abilities studying at the operating cool and fixed system of training which is the main form of the organization of training at domestic school causes general concern. "Preservation of traditional cool and fixed system, its basic element - a lesson leads to such phenomena as a formalism in an assessment of activity of teachers and pupils, an overload. In it many vital problems aren't solved" [Andreyev, 1988, 10].

In our opinion, realization of didactic potential of national pedagogic in which it is preferred as individual forms of education, promotes in a certain measure to elimination of the main shortcomings of cool and fixed system of training. At realization of experience of national pedagogic in educational process there are conditions for a combination of various ways of the organization of training (individual, pair, group and collective). Educational activity of school students is individualized, their creative abilities develop. As it was already noted, in national pedagogic training directly hanged from the importance of the trained kind of activity for the pupil. It was conducted surely taking into account abilities and the trainee's opportunities as formation of individual style of work played importance (especially when training in a professional layer of national knowledge). Leaning on the allocated V. I. Andreyev the principles of an individualization of educational and creative activity for self-education of creative abilities of the personality (Al-Farabi, 1970, 147, and, also considering specifics of national didactic experience, we defined the following principles of an individualization of study of school students in the course of realization of national ideas and experience of training:

a) the principle of the personal importance for pupils of this form of activity (study, game, productive work, etc.);

b) principle of the accounting of personal qualities, creative talents and opportunities of trainees;

c) principle of individual style of educational activity;

d) principle of optimism.

We will in detail stop on two last principles of educational activity individualization, including the first two of them known to the reader from pedagogical literature. Due to the principle of individual style of educational activity at 
development of experience of national pedagogic the following rules are recommended to teachers and pupils:

1) Blindly not to copy well-known methods and working methods, and to adapt them taking into account the abilities and a concrete situation.

2) Every time to look for the approach, the original method of the solution of a creative task.

3) To look for the rhythm, speed, style of activity (in game, study, work, sports and improving and art and esthetic activity) taking into account the strong qualities and weaknesses.

\subsection{Optimism Principle}

The principle of optimism demands creation of an optimistic spirit of pupils on possibility of achievement of the purpose even in a case of temporary failures. In the people experience there were peculiar methods and means of formation of positive emotions and strong-willed efforts at children at knowledge acquisition. Realization of didactic potential of national pedagogic surely is followed by creation of an optimistic spirit of pupils, both folk remedies of didactic work, and modern technological tools of impact on the emotional and strong-willed sphere of school students in the course of training.

\subsection{The moral principles}

The moral principles in realization of didactic potential of national pedagogic assume that the experience on all kinds of activity which is saved up by the people through many centuries was formed in indissoluble communication with its moral installations, moral values. The people attached paramount significance to development at children and youth of ethnic stereotypes of behavior, i.e. to their moral education. It is specified in pedagogical heritage of outstanding national thinkers that good moral education because the knowledge which is some kind of "weapon" can appear on hands of unscrupulous people has to precede any good training and be used by them in the bad purposes. Not for nothing in the people speak: "It is easy to become the scientist, it is difficult to be the person".

In didactic ideas of national pedagogic the intellectual is inseparable from the moral. Still great Al-Farabi in the treatise "About that Has to Precede Studying of Philosophy" wrote that "the condition of the person from which the Aristotelian doctrine is perceived, has to be such as it was already told, that is it has to correct, first of all, the nature so that properties of his sensual soul went to truth and only to truth, but not to pleasure. At the same time it is necessary to improve power of reasonable soul so that his will went to the truth" [Al-Farabi, 1970, 12-13]. Means, this principle also obliges teachers and pupils to clear the moral parties before starting mastering of knowledge and abilities, to use them during didactic processes, to respect ethical standards.

\subsection{Esthetic principles.}

In the people trained to follow rules of harmony, simplicity and beauty in everything. Studying of experience of national pedagogic has to be combined with such rules of simplicity and beauty, as:

1) To remember that the love for the country begins with love to the fine: "Only poor don't decorate with spirit the dwelling. Therefore, all what are you doing, - do simply and beautifully!"

2) To achieve simplicity in everything, to reject excesses ("Sugar in itself sweet" or "If is a lot of jewelry, the price won't be it" national proverbs about it sound).

3) To remember that in business it is necessary to try to approach the most real, the main, necessary: ("Conversation in essence is good", - speak in the people).

4) To remember that simplicity and beauty are reached by big and intense work: ("There is no pleasure without effort", "The work, the more sweet it a fruit is difficult", - advises the people to good fellows).

\section{The Results of the Research}

In general, the essence of didactic potential of national pedagogic consists in total the pedagogical knowledge, ideas, skills acquired in many generations of the people in the empirical way which in modern conditions can be considered through a prism of opportunities of their practical application in real teaching and educational process of comprehensive school. National didactic ideas and experience of training are considered in the context of realization of problems of ethno cultural education and the educational purposes at the level of a concrete step of school education, at the level of a subject or a separate lesson. 
Meanwhile, realization of didactic potential of national pedagogic in practice of teaching and educational process of school is connected with observance of system of the specific pedagogical principles. Treat them: the accounting of regional specifics of life of the people in the content of education and training; an optimum combination traditional and modern in educational and educational process; realization of experience of national pedagogic through all forms of activity of pupils; accounting of fundamental rules of national pedagogic; communication with programs of national development; individualization of educational activity and moral and esthetic principles. We will note that only complex application of the called fundamental rules of use of didactic opportunities of national pedagogic in teaching and educational process of national school is provided by the expected results of improvement of quality of training and education, formation of ethno cultural competences of the identity of the graduate of school.

\section{References}

Al-Farabi. 1970. Filosofskiye traktaty [Philosophical tractatus]. Almaty.

Andreyev, V.I. (1988). Dialectic of education and self-education of the creative person. Kazan: Publishing house Kazan.

Atamuratov, S. (1991). National consciousness and international education. Tashkent: Uzbekistan.

Boguslavsky, M.V. (1998). Universal and national valuable orientations of domestic pedagogic (beginning of the XX century). Pedagogika, 7, 82-87.

Dyachenko, V.K. (1989). Organizational structure of educational process and its development. Moscow: Pedagogika.

Kaliyev, S., Imasheva, A. (2009). History and theoretical fundamentals of the Kazakh ethnopedagogics. Almaty.

Kharlamov, I.F. (1997). Pedagogic. Moscow: Yurist.

Konstantinov, I.A., etc. (1982). Pedagogic history. Moscow: Education.

The concept of ethno cultural education in the Republic of Kazakhstan. (1996). Teacher of Kazakhstan, August 14.

Kozhakhmetova, K.Zh. (1998). Kazakh ethno pedagogic: methodology, theory, practice. Almaty.

Orlova, A.P. 1991. To national school - experience of national pedagogic (20th, 30th). Sovetskaya pedagogika, 7, 88-91.

Standard programs for schools with the Uzbek language of training of the Republic of Kazakhstan. (2012). Astana.

Volkov, G.N. (2003). Ethno pedagogy. Moscow: Academy.

Yalalov, F.G. (2004). Ethnodidactics. Moscow: VLADOS. 